\title{
EXPECTED COOLING OF THE EARTH AND ITS IMPLICATION ON FOOD SECURITY
}

\author{
Dr. Shahinaz M. Yousef**
}

\begin{abstract}
Solar induced climate fluctuations are crucial to life in earth. When weak solar cycles are predominant on the sun, cooling occurs on the earth. The present solar cycle number 23 is the first of a weak cycles series on the sun. This eventually will lead to drops in the solar energy budget received by the earth including drops in solar irradiance, $U V$ radiation which plays a vital role in photosynthesis and IR radiation.

Biological effects will happen on the earth. It is found that fish population is very much controlled by the Solar (80-120 year) Wolf-Gleissberg cycles.

The problem of disappearance of sardine from the eastern Mediterranean in 1964 previously attributed to the side effects of the High Dam can be explained in the context of sun-earth connection. Sardine disappeared at the same time from the coasts of California, Japan and Chile. Also contemporary herring fish disappearance occurred in the North Sea off the shores of Norway and Siberia. Solar induced climate change occurred at the same time with change in the general wind circulation.
\end{abstract}

* Department of Astronomy \& Meteorology, Faculty of Science, Cairo University.

-53- 
This climate change of the 1960s can be attributed to the drop of solar activity level and the appearance of a weak solar cycle( number 20) following the maximum of the Wolf-Gleissberg cycle causing acceleration in the spinning of the sun.

We may thus conclude that the global cyclic variations in fishery are interrelated and that they are dominated by Wolf-Gleissberg cycles through the induced variation of various types of radiations that are absorbed in marine water at different depths leading to variation in sea surface temperatures suitable for the very existence of different kinds of fish. The abundance of seaweed is also governed by the level of solar activity in order to match the variation of populations of marine species.

The potential impact of global cooling on agriculture is of uttermost importance for food security. Earlier investigators estimated that a one degree drop in European temperature will lead to a drop of the number of people sustained by one hectare from three individuals to two and to the possibilities that one fifth of the world population will be subjected to hunger. Investigators are encouraged to apply computer models to study the effect of cooling in different countries on the yield of agriculture and work out the suitable crops to be cultivated and perhaps cultivation of the present crops ought to be shifted to lower warmer latitudes.

The Egyptian government is urged to put forward a revised strategy taking into account the expected cooling effect.

\section{THE IMPORTANCE OF THIS STUDY}

The Earth's weather machine is an exquisitely complex affair, in which many processes are simultaneously at work. Clearly however, the weather system is principally driven by the sun (Roberts, 1976).

Solar radiation is an unfailing source of energy for the Earth. Without visible and infrared (IR) radiation from the sun, Earth's surface temperature would be too cold to support life. Nor would there be energy to fuel photosynthesis or power the circulation of the lower atmosphere and oceans that profoundly influence living organisms. Lack in solar ultraviolet (UV) radiative inputs, Earth's middle atmosphere would be devoid of ozone and its upper atmosphere cold and unionized. Living things would be exposed to damaging high energy solar photons (Lean, 1997). 
All of those solar radiative outputs in addition to the corpuscular radiation are Wolf-Gleissberg cycle (80 year cycle) dependant variables.

The subject of sun- earth connection has a great impact on world economy.

Climatic fluctuations, which are related to the Wolf-Gleissberg cycles, are very crucial to life on earth. In the 1970s, the CIA encouraged research in climatic fluctuations because of its implication on food production and political instabilities. It was found that optimum climatic conditions between 1930-60 was ideal for green revolution in world food production and that there is a likelihood to return to the $19^{\text {th }}$ century climate characterized by marked drop in global temperature and wide spread drought-flood hazards that led to many revolutions and political instabilities. It is estimated that a one degree drop in European temperature will lead to a drop of the number of people sustained by one hectare from three individuals to two and to the possibilities that one fifth of the world population will be subjected to hunger (extracted from Abu El Ezz (1980) short translation of CIA book "The Weather Conspiracy: the coming of the new ice age").

Since there are indications that changes in the solar energy output influence the Earth's climate on time scales ranging from the WolfGleissberg cycle up to the Maunder type of climate anomalies (drop of solar activity leading to the little ice age), and since persistent variations in total solar irradiance over a century could have explained a wide range of climatic changes that occurred in the past (Pap and White 1994), therefore studying the effect of the Wolf-Gleissberg cycle on terrestrial phenomena can improve our understanding to sunearth connections which can lead to long range forecast of various terrestrial responses and climatic fluctuations.

Agriculture is the basic activity by which humans live and survive on the earth. Assessing the impacts of climate change on agriculture is 
a vital task. In both developed and developing countries, the influence of climate on crops and livestock persists despite irrigation, improved plant and animal hybrids and the growing use of chemical fertilizers. The continued dependence of agricultural production on light, heat, water and other climatic factors, the dependence of much of the world's population on agricultural activities, and the significant magnitude and rapid rates of possible climate changes all combine to create the need for a comprehensive consideration of the potential impacts of climate on global agriculture (Rosenzweig and Liverman, 1992).

Fishery and livestock are also dependant on solar variability.

\section{SOLAR ACTIVITY CYCLES}

Naked eye sunspots were observed in antiquity. The Arabic astronomer Abu Alfadhl Giaafar followed a sunspot for 91 days in A.D. 807 (Hoyt and Schatten, 1997).

The number of sunspots vary in a cyclic fashion. According to Nesme-Ribes et al. (1994), three types of solar cycles can be defined

Normal solar cycles in which

* The length is approximately 10 to 11 years.

* The sunspot number is large, and roughly symmetrical about the equator.

GM cycles( Maunder minimum type) in which

* The length is approximately 9-10 years.

* The sunspot number is small, largely asymmetric.

Weak cycles, in which

* The length is possibly greater than 11-yr.

* The sunspot number is small (compared with normal cycles), but shows little north-south asymmetry. 


\section{WOLF-GLEISSBERG SOLAR CYCLES}

The only continuous solar observations that extend over the important climatic time scale of decades to centuries are those of sunspots, yielding a measure of magnetic activity (Reid, 1995). There is evidence for a modulation of the amplitude of the 11 year solar cycle in a period of about 80 year known as Wolf-Gleissberg cycle. Although sunspot numbers may be traced back with confidence only about two and half centuries, auroral records have been used to trace the level of activity back more than 2 millennia. Other long periods that have been reported are 200,400 and 600 years (Howard, 1977).

The Gleissberg cycle manifest itself in total activity, cycle lengths, sunspot structure and probably other parameters for which we do not have sufficiently long time series(Hoyt and Schatten, 1997).

Eighteen years simple moving average smoothing of the mean annual sunspot numbers $\left(\mathrm{R}_{\mathrm{z}}\right)$, including prediction, is shown in Fig $2 \mathrm{a}$ (revised from Yousef, 1995). This figure shows three solar episodes super imposed on them, are the 11-year solar cycles. Downturn of solar episodes occurred during cycles 5 and 6 in the first minimum ((the Dalton minimum) and 12 to 14 in the second minimum. Further 18 years filtering of the smoothed data almost annihilates the superimposed 11 years cycles and thus the solar Wolf-Gleissberg cycles stand up clearly in Fig $2 \mathrm{~b}$. The two minima occurred during the years (1810-1811) and 1901, with 90 years separating interval. Figure $2 \mathrm{~b}$ is quite similar in part to the secularly smoothed values of auroras frequency numbers for each decade, (Gleissberg, 1971) and to the smoothed solar constant (Schatten and Orosz, 1990). From the above results, we must expect a third minimum early in the $21^{\text {st }}$ century (Yousef, 1995).

Table I reproduced from Yousef (1995) shows the characteristics of the last three Wolf-Gleissberg cycles as well as the coming one. The 80 year periodicity is also found in Nile water (Yousef and El Rae, 1995). 
Table 1. Characteristics of Some Recent Solar-Wolf-Gleissberg Cycles Showing The Dates of their Turning Points.

\begin{tabular}{|c|c|c|c|c|}
\hline Cycle & $\mathbf{1}$ & $\mathbf{2}$ & $\mathbf{3}$ & $\mathbf{4}$ \\
\hline $\begin{array}{c}\text { Duration of } \\
\text { Min. }\end{array}$ & & $1797-1823$ & $1877-1913$ & $1997-2032$ \\
\hline $\begin{array}{c}\text { Smoothed } \\
\text { Min. }\end{array}$ & $1727-28^{*}$ & $1838-1840$ & $1957-1958$ & 2009 \\
\hline $\begin{array}{c}\text { Smoothed } \\
\text { Max. }\end{array}$ & $1778-1780$ & 1860 & 1981 & \\
\hline $\begin{array}{c}\text { Secondary } \\
\text { Max. }\end{array}$ & 1776 & 1854 & & \\
\hline Allen 1973 & 1701 & \\
\hline
\end{tabular}

- First maximum of the cycle was added to the table after checking the list of sunspot number listed in Hoyt and Schatten (1997). It is lower than the secondary maximum contrary to the situation for cycles 2 and 3.

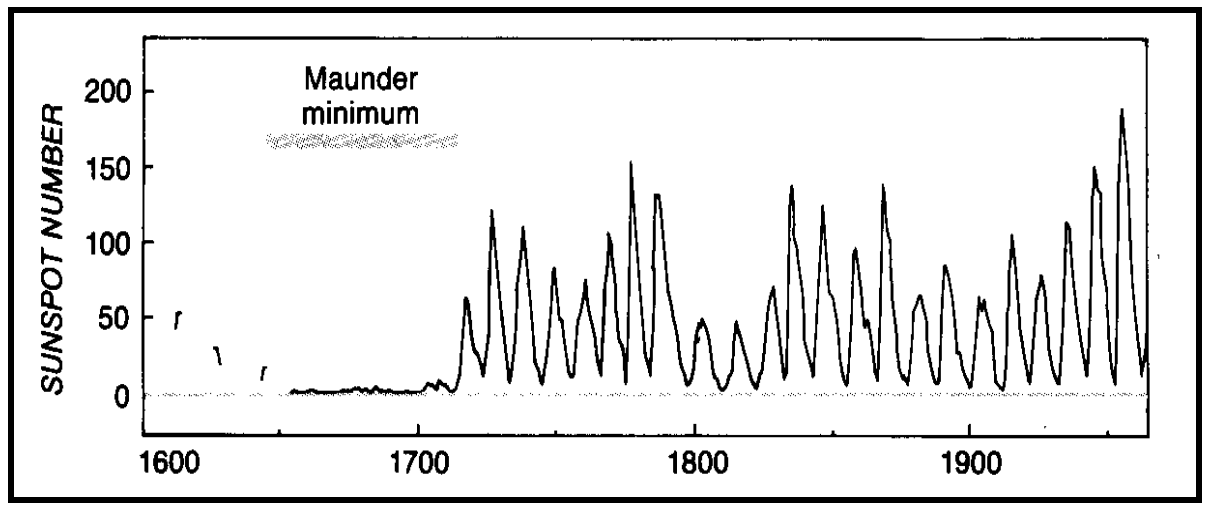

Fig. (1): Time series of annual mean sunspot number. Note three types of Solar activity cycles. Notice the weak cycles around 1800 and 1900. 


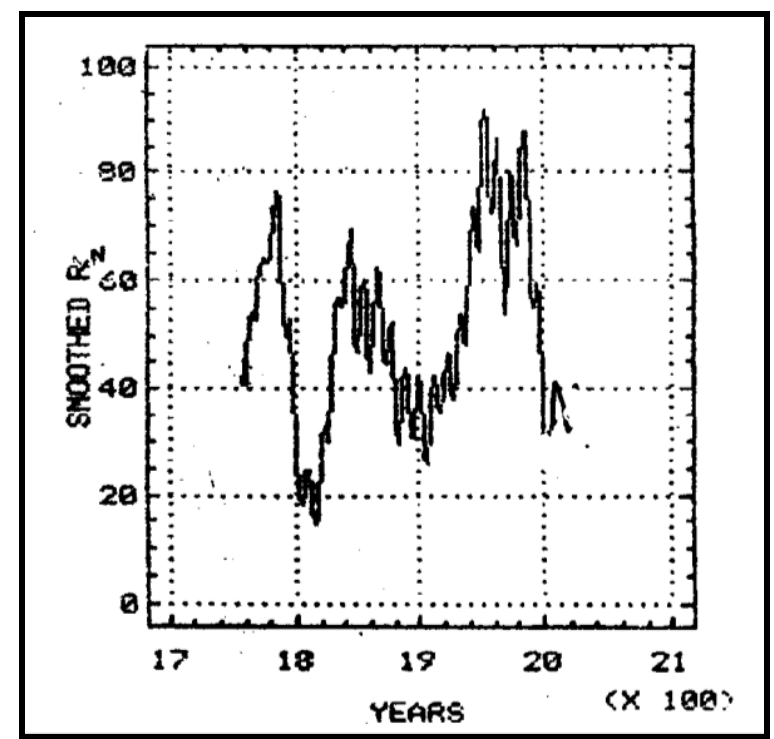

Fig. (2a): 18 years smoothed Wolf Sunspot Number showing the Wolf-Gleissberg cycles, superimposed on them are the sunspot cycles. Note the present downturn of solar activity.

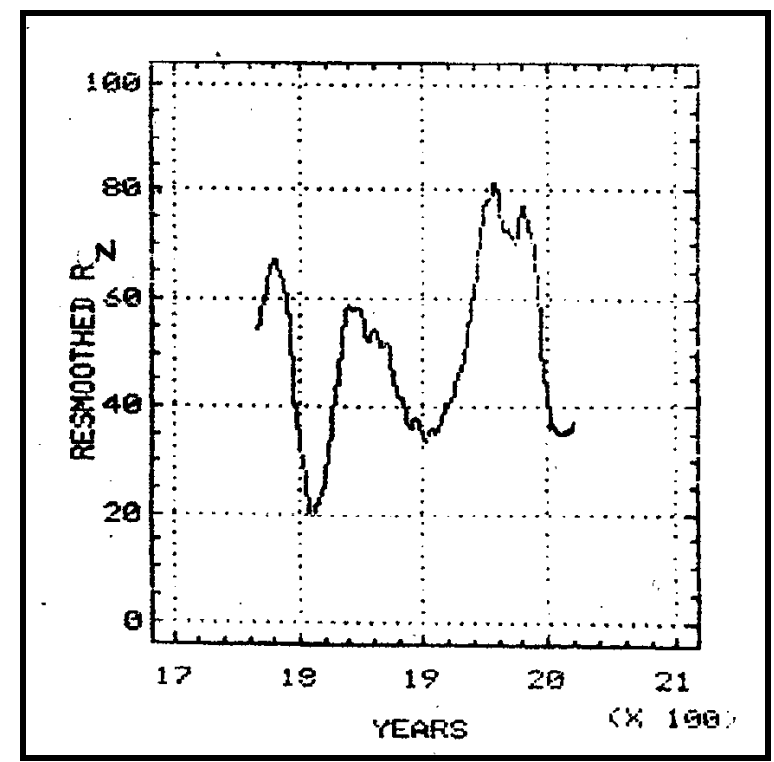

Fig. (2b): Further 18 years smoothing of Figure (2a) showing the Wolf-Gleissberg cycles.

$-59-$ 


\section{SOME ASPECTS OF CLIMATE AFFECTING FOOD PRODUCTION}

Several factors can affect plant growth and animal production. Among these factors are; solar irradiance, solar UV, precipitation and cloud cover, duration of day and night and temperature. Most of these parameters are driven by solar forces as will be shown below as they follow the pattern of Wolf-Gleissberg cycles.

\section{A) Solar Irradiance, UV and IR}

The first real breakthrough in solar total irradiance measurements came with the advent in radiometers on spacecraft launched in late 1978. Variation with the 11 year cycle in the case of solar cycles 21 and 22 is of the order 0.1 percent( Reid 2000 and references therein). Bigger change can be expected on a long term scale (Roederer, 1995 and references therein).

Model estimates of long-term variability in total solar irradiance and in the two spectral bands UV and IR produced in figure (3) adapted from Lean (2000) show Wolf- Gleissberg cycles pattern.

When computing their solar- irradiance model, Hoyt and Shatten (1997) only used two parameters

1. The amplitude of the solar cycle variation and

2. The amplitude of the Gleissberg cycle variation.

The first parameter based on the Nimbus-7 observations. The second parameter is chosen so that the Maunder Minimum (16451715 AD) will be about $0.25 \%$ less bright than the modern sun. 


\section{B) Cosmogenic isotopes.}

From the extant historical sunspot records, only three WolfGleissberg cycles can be discerned. Recent techniques using cosmogenic isotopes have constructed solar activity on longer time scales. Two isotopes are commonly used, carbon-14 and Be-10, both produced by cosmic rays. Galactic cosmic rays are modulated by changes in the strength in interplanetary magnetic field arising from changes in solar activity. Hence measurements of the isotope concentration as a function of time provide proxy measures about the history of solar activity. Figure (4) shows the resemblance of the Be10 long term variation to the solar Wolf Gleissberg cycle. Cosmogenic isotopes serve as nuclei for water drops forming clouds.

\section{C) Precipitation}

Figure $5(\mathrm{a}, \mathrm{b}, \mathrm{c})$ represents successive 18 years filtering followed by another 18 years of annual precipitation in both England - Wales and India. In comparison, similar filtering is performed for sunspot number showing solar Wolf-Gleissberg cycles. It is quiet clear that the roots of this cycle are coincident with the minima of both the English-Welsh and Indian precipitation cycles and that they are all in coherence.

However there are two precipitation cycles within one solar Wolf- Gleissberg cycle, with a precipitation minimum around the maximum of solar Wolf-Gleissberg cycle.

\section{D) Global temperature}

The annual mean global air temperature track the sunspot cycle length as shown in fig 6 implying that the solar cycle length represents the climatic relevant part of the solar variation (Roederer, 1995). Those patterns are also Wolf-Gleissberg patterns. 


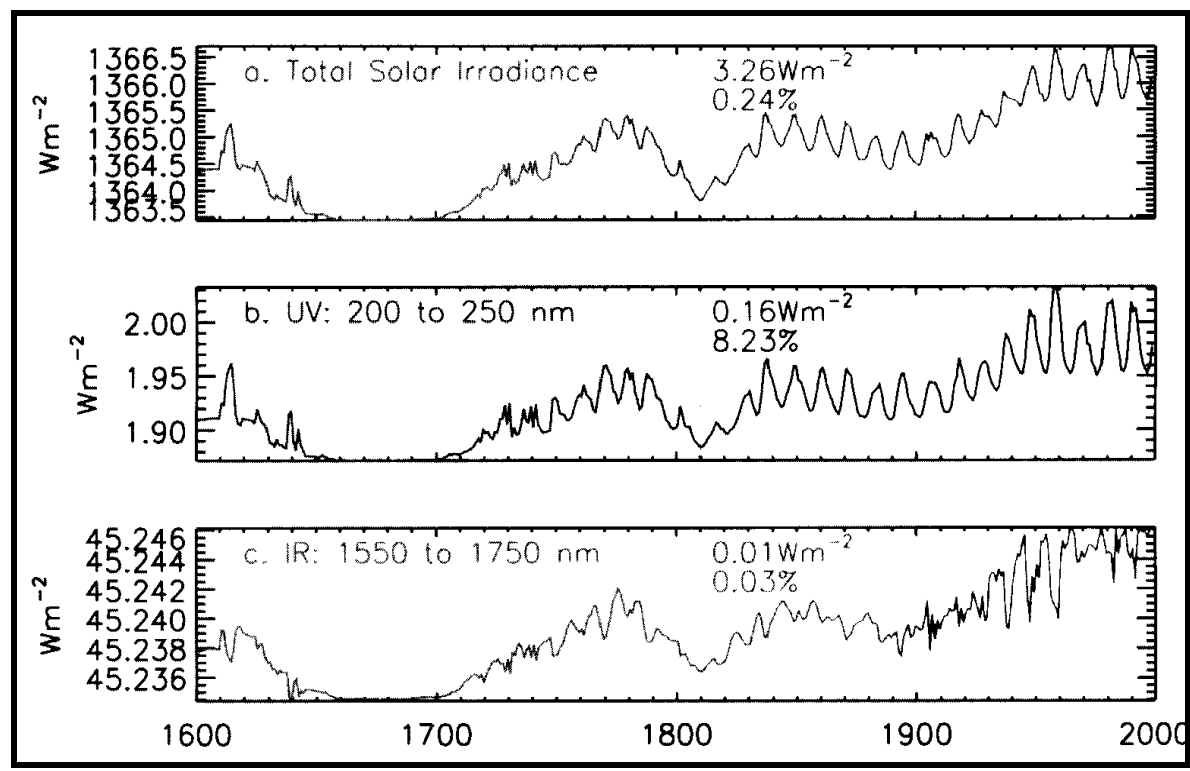

Fig. (3): Model estimate of long-term variability in total solar irradiance and in two spectral bands in the UV and IR showing the Wolf-Gleissberg cycles (after Lean 2000).

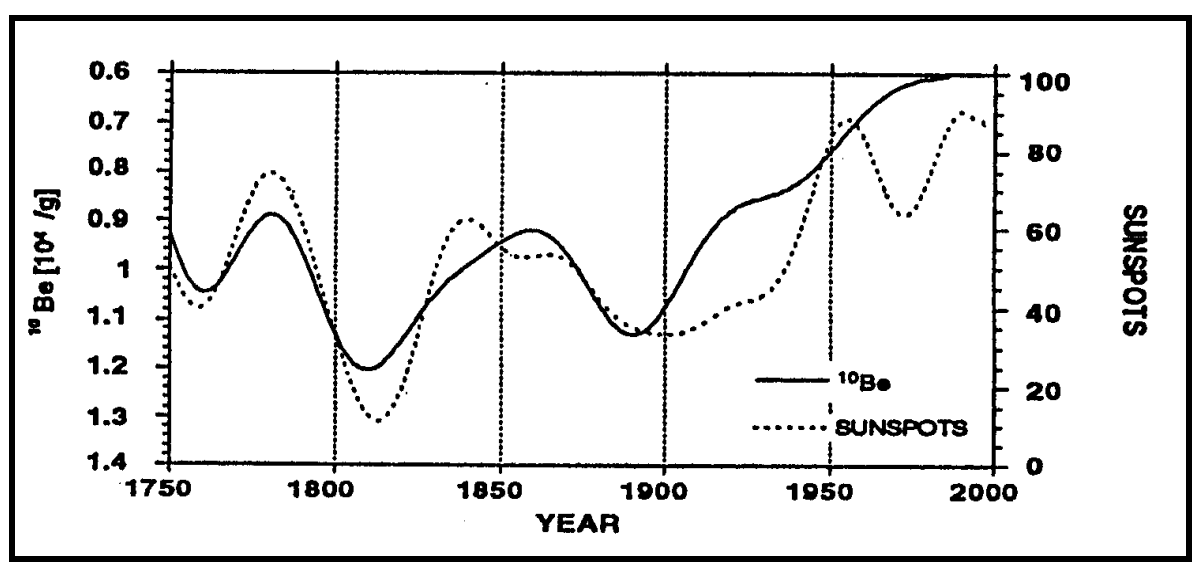

Fig. (4): Coherence between long -term variation of Be isotope (solid curve) and Solar Wolf Gleissberg cycles(dotted curve) showing the Dalton minimum around 1800 and a lesser solar activity minimum around 1900( after Hoyt and Schatten, 1997 and his reference). 


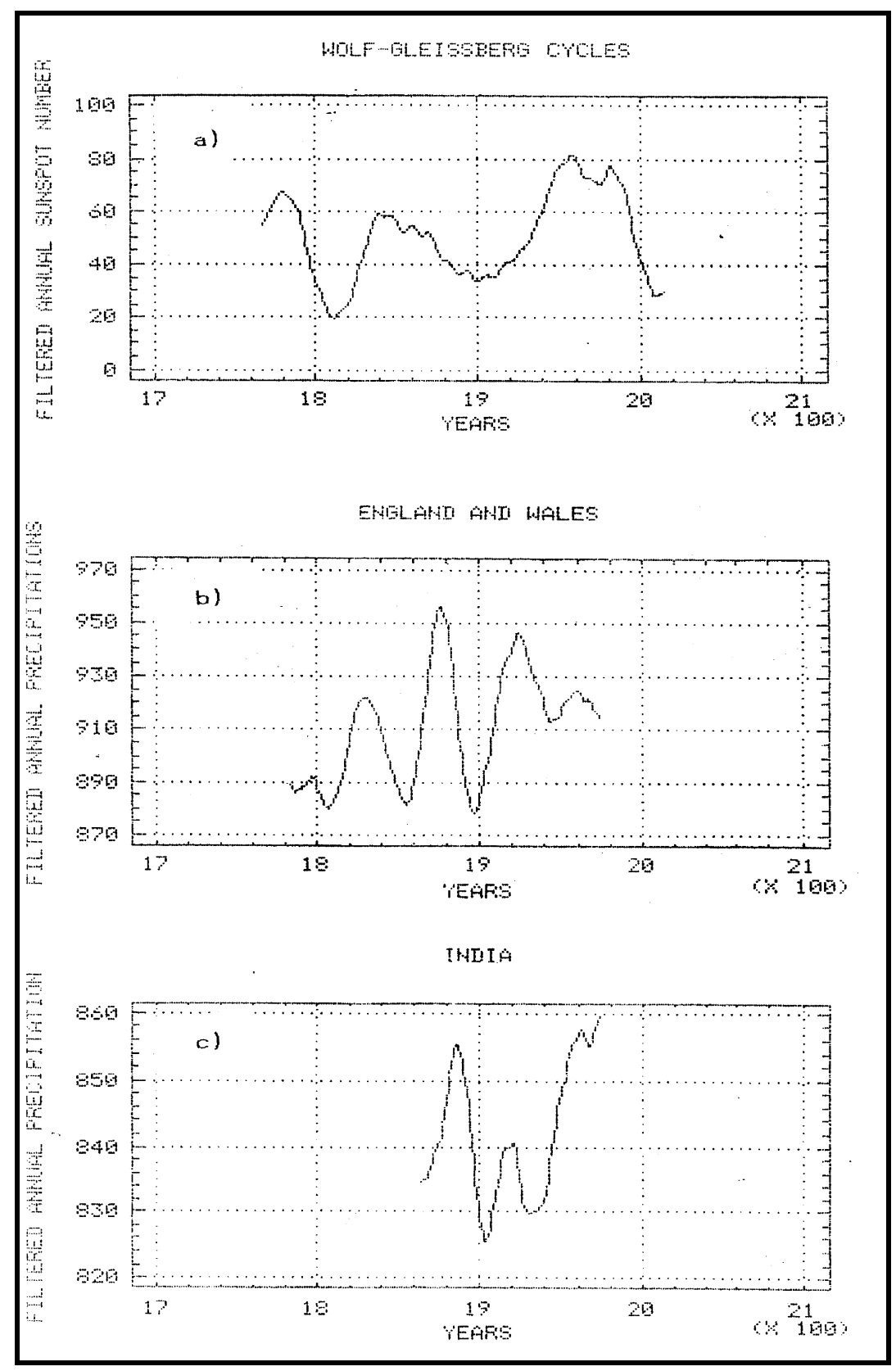

Fig. (5): Coherence between Solar Wolf- Gleissberg cycles and precipitation cycles for England-Wales (b) and India (c).

-63- 
The global average sea surface temperature (SST) shown in figure (7) (adapted from Roederer1995) and his reference also remarkably show the Wolf- Gleissberg pattern.

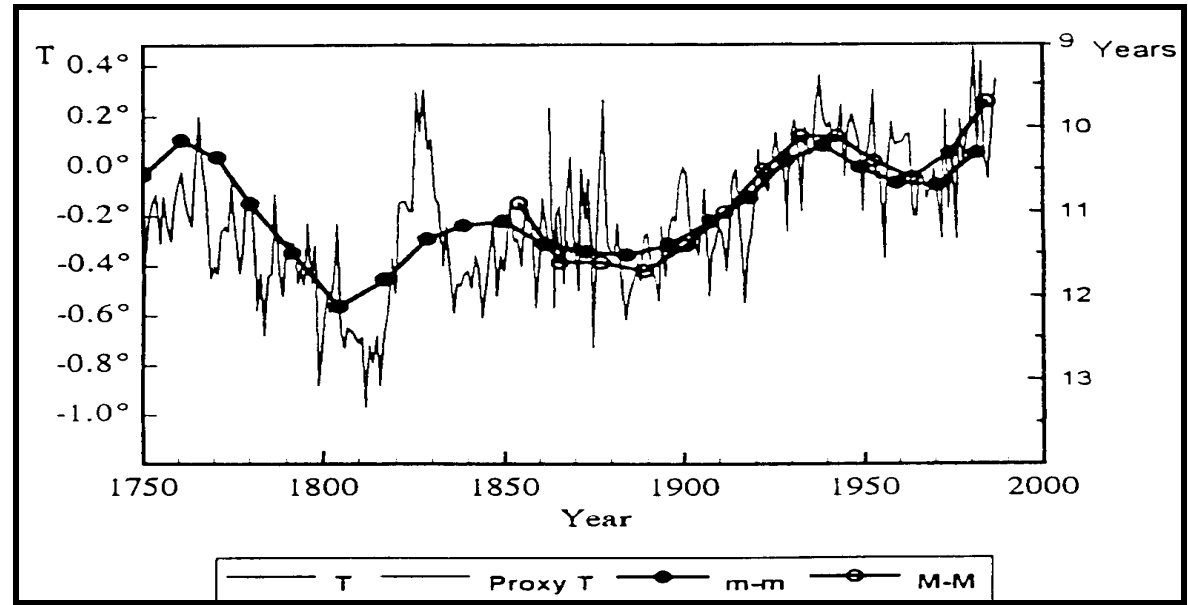

Fig. (6): Annual average of the northern hemisphere air temperature (thin curve) and appropriately filtered values of the sunspot cycle length (solid curve) determined independently by means of sunspot minima (m-m) and maxima (M-M), note reverse scale, all showing Wolf-Gleissberg cycles (adapted from Roederer, 1995 and references therein).

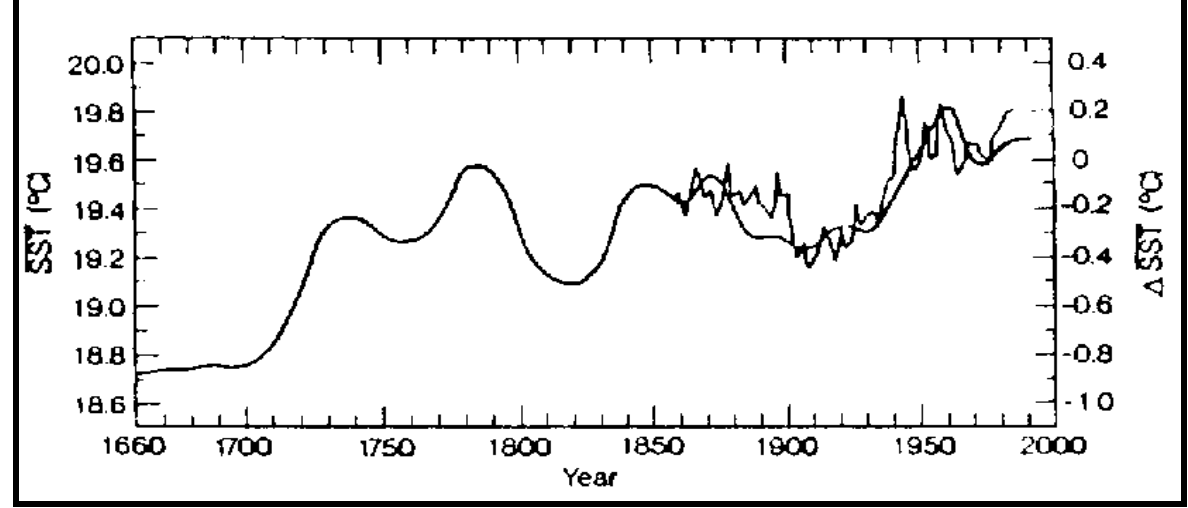

Fig. (7): The sea surface pattern seem to resemble the Wolf-Gleissberg cycles with temperature drop during the time of intermediate weak solar cycles around 1800 and 1900. Similar drop occurred during the little ice age. 


\section{THE OCCURENCE OF CLIMATE FLUCTUATIONS AT THE TURNING POINTS OF WOLF-GLEISSBERG CYCLES}

It is noticed that climatic fluctuations do occur at the dates of turning points shown in Table (1) and Fig. (8). reproduced from Yousef (2000 a). Review of climatic fluctuations is given below.

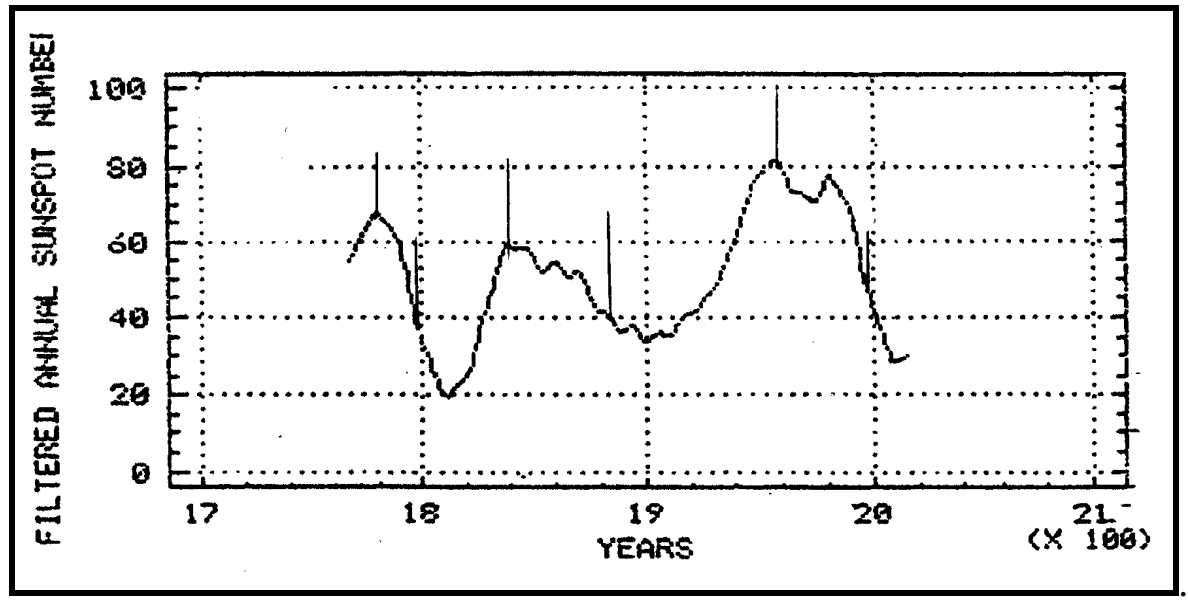

Fig. (8): Re-smoothed sunspot numbers showing three Wolf- Gleissberg cycles. The vertical lines indicate the dates of turning points at which climate fluctuations occur.

Sudden rise (or fall) of Lakes occur at the turning points indicating the onset of climate fluctuations. Note that climate fluctuation (change) occurred in the early sixties just following the maximum of the previous Wolf-Gleissberg-cycle, and consequently must have occurred at pervious maximums around 1780 and 1838-40. At the termination point of Wolf-Gleissberg cycle and the beginning of weak intermediate solar cycles in 1878, Lake Victoria rose sharply indicating the onset of climate fluctuations and the beginning of an era or severe El Ninos and La Ninas causing several decades of droughtflood hazards. Earlier climate fluctuation must have occurred around 1797. Recently, in 1997-98 another sharp rise of Lake Victoria occurred marking the end of the last Wolf-Gleissberg cycle and the start of solar cycle number 23 which has proved to be considerably weaker than its previous cycles. 1997-98 is the onset of climate 
fluctuation which would be similar to that of 1797 . The coming era is believed to be a recurrent of the frequent natural hazards that happened around 1800. Other climate fluctuations occur at the build up of new Wolf-Gleissberg cycles e.g. as happened in 1922. Another similar climate change must have occurred at the end of Maunder minimum (1645-1715)- which coincided with the maximum of little ice age- and beginning of Wolf-Gleissberg cycles.

Cycle 19 (at the maximum of Wolf-Gleissberg cycle) was the most active cycle for centuries. It was followed by cycle 20 which is rather a weak cycle. The solar rotation rate increased with cycle 20 which must have lead to drop in solar irradiance (Hoyt and Schatten, 1997 and references therein) and solar induced climate change resulted.

\section{Expected Cooling of the Earth}

\section{A) Land-Air Temperature:}

1878 drop of temperature

Figure (9) Shows the drop of air -surface temperature for three sites in Great Britain. It is evident that temperature drop occur in between Wolf-Gleissberg cycles when intermediate weak small amplitude sunspot start to occur in 1878. The temperature drop indicate climate fluctuation marking the end of a Wolf-Gleissberg cycle. The sudden rise of temperature points to another climate fluctuation indicating the development of a new Wolf-Gleissberg cycle and end of small amplitude solar cycles (Hoyt and Schatten, 1997).

Five degrees drop of temperature for the small town of Sorya in Spain (Donaire 2000) starting 1878 indicating climate fluctuation as seen in figure (10) in coincidence with the termination of WolfGleissberg cycles and start of another type of low amplitude solar cycles. It is very important to note that there has been considerable warming prior to that drop. 


\section{Drop of Temperature for Southern Mediterranean sites}

Aesawy and Hasanean (1998) studied the annual and seasonal climatic air temperature variations at six southern Mediterranean stations, Alger (1823-1991). Tripoli (1944-1991), Alexandria (19421991), Amman (1923-1991) and Beirut (1863-1991). They report abrupt climatic changes towards warm or cold periods. Very distinct cooling occurred in Alger (fig 11) coincident with the time of weak solar cycles and drop of solar irradiance. This cooling can be compared with the cooling of Soria shown in figure (10).

From figures $(9,10$ and 11), it is evident that solar forcing due to the drop of solar activity level and the termination of normal solar cycles and consequently due to the start of weak solar cycles and change it the rate of rotation of the solar atmosphere lead to drop of solar energy budget reaching the earth. This phenomena lead to climate change on the earth starting 1878 as manifested by global cooling.

Since the present solar cycle number 23 is a rather weak cycle, and following this line of thought, it is thus expected that cooling would happen rather soon. There might be time lag between the start of cooling at different locations.

On the other hand, Aesawy and Hasanean (1998), figure for Alexandria temperature variation shows warming up till about 1961 followed by cooling. Since climate change occurred around 1961 with change in the general wind circulation (Lamb, 1966) following the maximum turning point of the Wolf-Gleissberg cycle as shown in fig. (8), thus we can conclude that the rise and fall of the temperature of Alexandria for this period was due to solar forcing.

\section{B) Evidence from Sea Surface Temperature Variation}

Figure (12), after Reid (2000) shows an example of the kind of correlative evidence used to support claims of the relationship between solar activity and global climate. In this case, the solar parameter is the 11- running mean of the annual sunspot number, and the departure of the globally averaged sea-surface temperature from the long-term average. Sea-surface temperatures (SSTs) have been measured on a routine basis by ocean going ships since the middle of the $19^{\text {th }}$ century. 


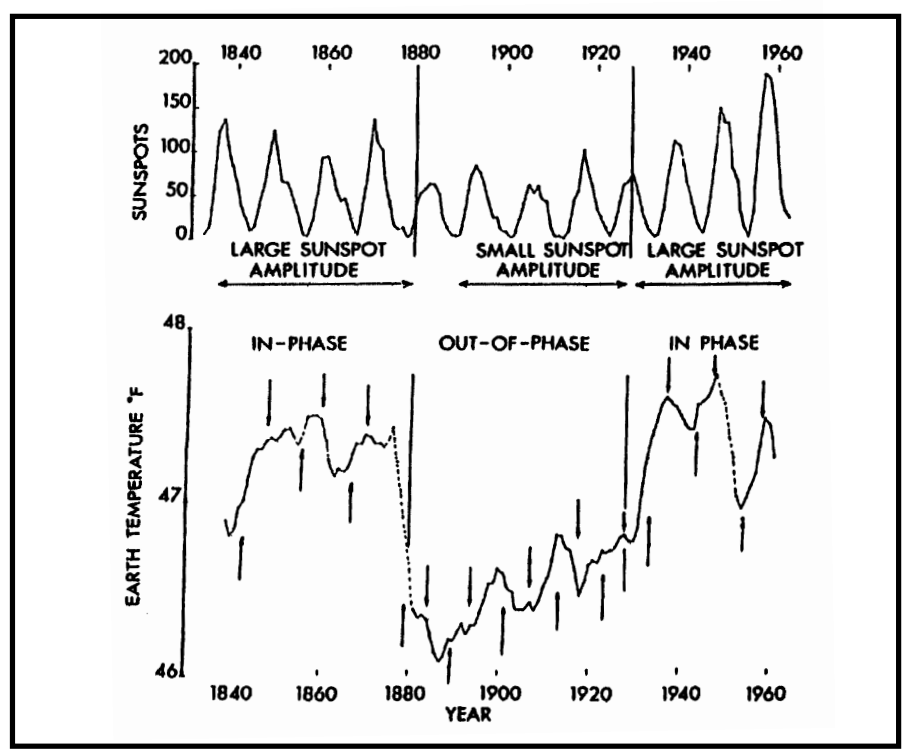

Fig (9): Air surface temperatures from Edinburgh, Wakefield, and Greenwich in Great Britain shown with Wolf sunspot Numbers. Temperature appear to be out of phase with solar activity from 1880 to 1930, but in phase for other years (Adapted from Hoyt and Schatten 1997 and references therein)

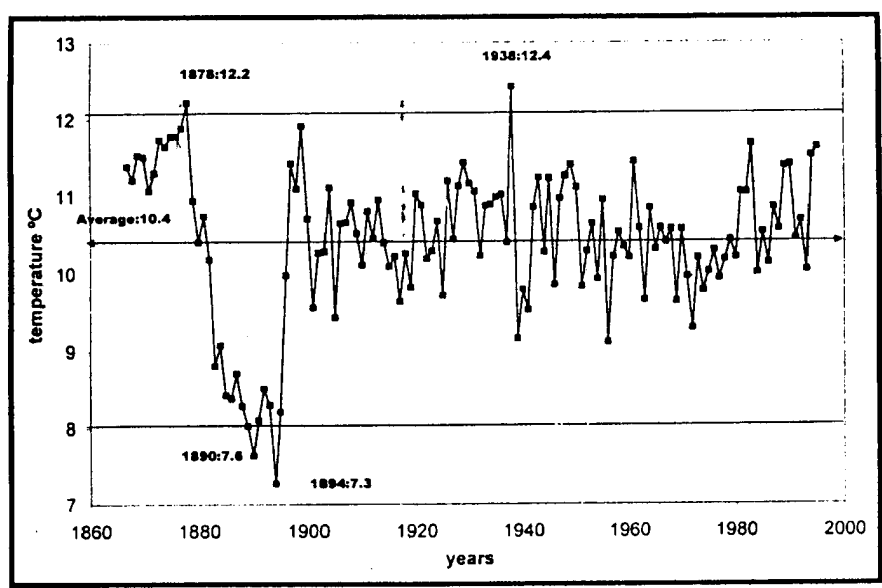

Fig. (10): Temperature anomalies in Soria, a small town in Spain. Adapted from Donaire (2000).Notice the 1887 drop of temperature indicating climate fluctuation. Prior to this drop there has been more than a half a degree rise in temperature. 


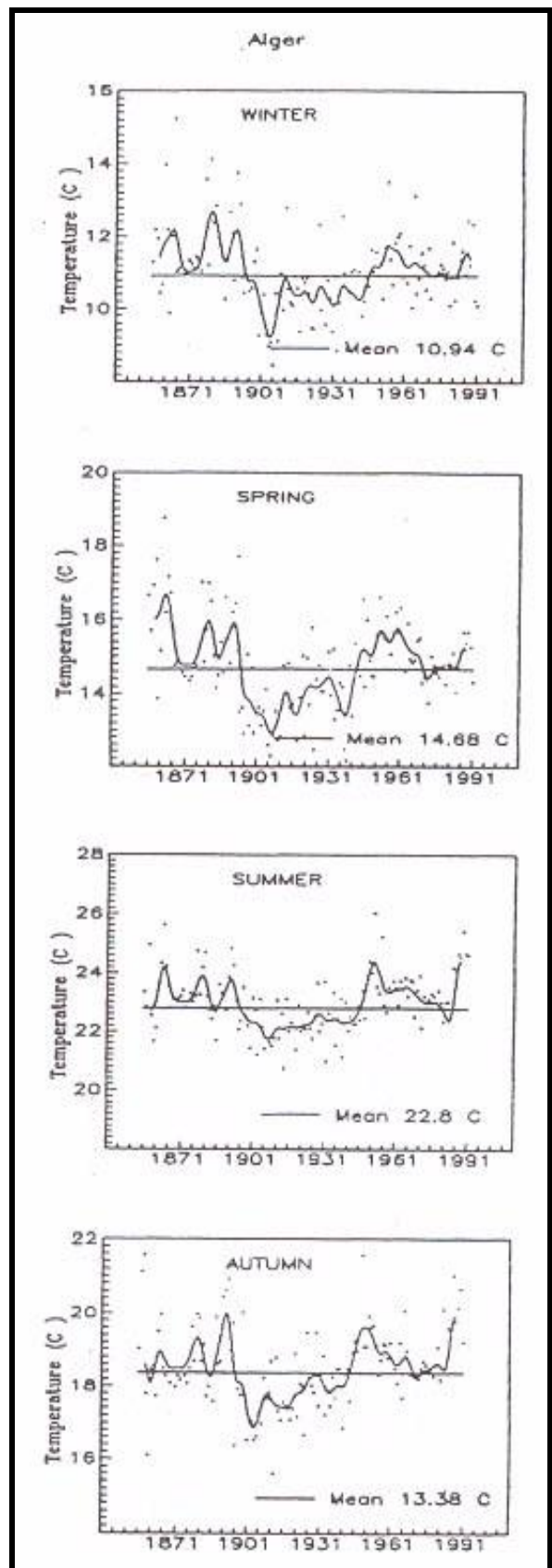

Fig. (11): Seasonal fluctuations of Temperature for Alger.

$-69-$ 

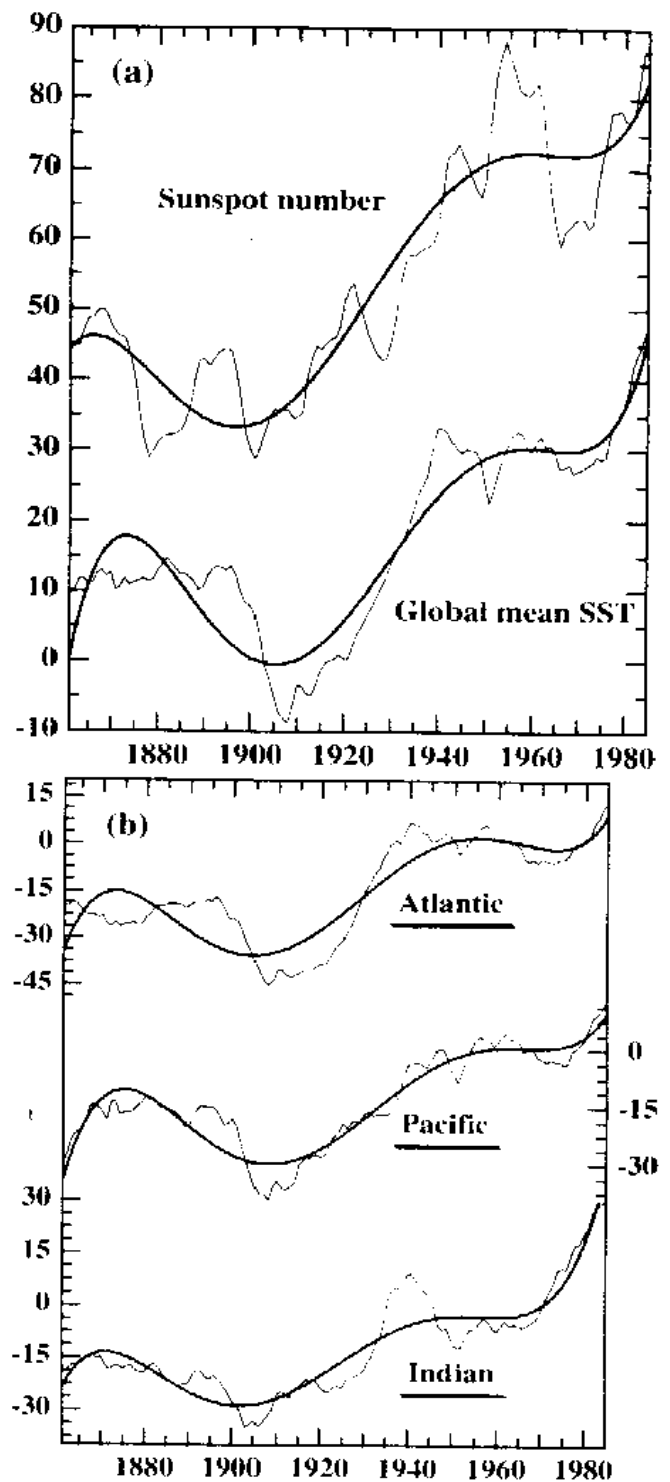

Fig. (12a): Eleven yr. running means of the annual sunspot number (i.e. WolfGleissberg cycle) and mean global mean sea surface temperature shown as departures from the 1951-80) average in units of $0.01 \mathrm{k}$ (lower light curve). Heavy curves are least squares $7^{\text {th }}$ degree polynomial fits to the data. (b) Same as (a) for the three major basins (after Reid, 2000). Note the striking control of the solar WolfGleissberg cycle on SST of major oceans 
Figure (12b) shows the 11-year running mean SST data averaged over each of the three main ocean basins, and the overall similarity of the least square polynomials is a strong indication that the temperature variation is truly global in nature. The cooling around the turn of the century appears every where, and is coincident with weak solar cycles, and is followed by a warming from 1920 through about 1950s (Reid, 2000), i.e. warming goes with the development of the Wolf-Gleissberg cycle through its maximum as is evident from figure (12) a. These arguments compel us to consider a forcing mechanism in the sun itself, being the source of terrestrial climate change.

\section{Effect of Temperature Fluctuations on Food Security}

\section{A) Fisheries: The Atlanto -Scandian Herrig Fishery Case}

The Baltic and North Sea herring fisheries underwent sharp changes alternating with each other in a way that had obvious climatic significance (Lamb, 1982).

The Atlanto-Scandian herring fishery began about one thousand years ago. Traditionally the main fishery of adult herring had been a winter fishery along the Norwegian west coast. Figure (13) shows the catches of winter herring off the western Norway. It is evident that the number of catches follow two Wolf- Gleissberg closely.

The number of catches was very low around 1800 and 1900, i.e. during the weak solar intermediate cycles. The number of catches rose from several hundred metric tons in 1810 to 70,000 metric tons in 1830 and reaches a maximum of 100,000 metric tons during the 1860 secondary maximum of Wolf-Gleissberg cycle and then declined in 1870s. In 1880 s and 1890 s, the annual catches totaled only 13,000 metric tons. The number of catches rose again with the development of the following Wolf-Gleissberg cycle reaching a peak of 10 million metric tons in 1957(maximum of Wolf- Gleissberg cycle) and then declined sharply to 3 million metric tons in 1963. The decline of herring fishery extended also to USSR and Iceland ending with the collapse of the Scandian herring stock (Krovnin and Rodionov, 1992). 
During the 1960s, the intensification of fishing pressure coincided with pronounced change in the regional climate. Analysis of about a thousand years of Herring fishery indicated that there had been analogous situations in the past, when fishery disappeared. Before its disappearance toward the end of the previous century, the fishery tended to shift northward. A similar situation was observed in 1950s -1960s.

Since the herring normally inhabit waters with temperatures between 3 and $13^{\circ} \mathrm{C}$ (Lamb, 1982), then the Wolf-Gleissberg pattern evident in figs $2 \mathrm{a}$ and 13 actually is a biological temperature time series off western Norway. The increased abundance of Herring should also reflect abundance of food necessary to sustain the fish. It is found that e.g. that the density of seaweed off the shore of Scotland follow exactly sunspot cycles for the years 1946 to 1955 (Hoyt and Schatten 1997 and references therein).

\section{The Sardine Catches Case}

The problem of disappearance of about $95 \%$ of the sardine fishery from the eastern basin of the Mediterranean was attributed to the High Dam holding the Nile water from going into the Sea by 1965 (El Kassas, 2000). This might be the case, however it may be that the sardine fishery declined in analogy to the Herring fishery. This problem can be solved if historical declines were reported in the past or the sardine disappearance is reported at the same time elsewhere.

Indeed, this is evident from the title of the article of Ueber and MacCall (1992) entitled "The rise and fall of the California sardine empire".

Figure (14) reproduced from Kawasaki (1992), shows the fluctuations in three major sardine populations in the Pacific; the Far Eastern waters around Japan, the California sardine off the west coast of North America and the Chilean sardine off the Chilean coast. Around 1960, when the Japanese sardine stock was at low level, it was confined to a small coastal area along southern Japan. However in the 1980s, when the stock was abundant it spread throughout the Sea of Japan.

During the decline period of Far Eastern sardine, a three-year old fish increased in length from 18 to $20 \mathrm{~cm}$. 


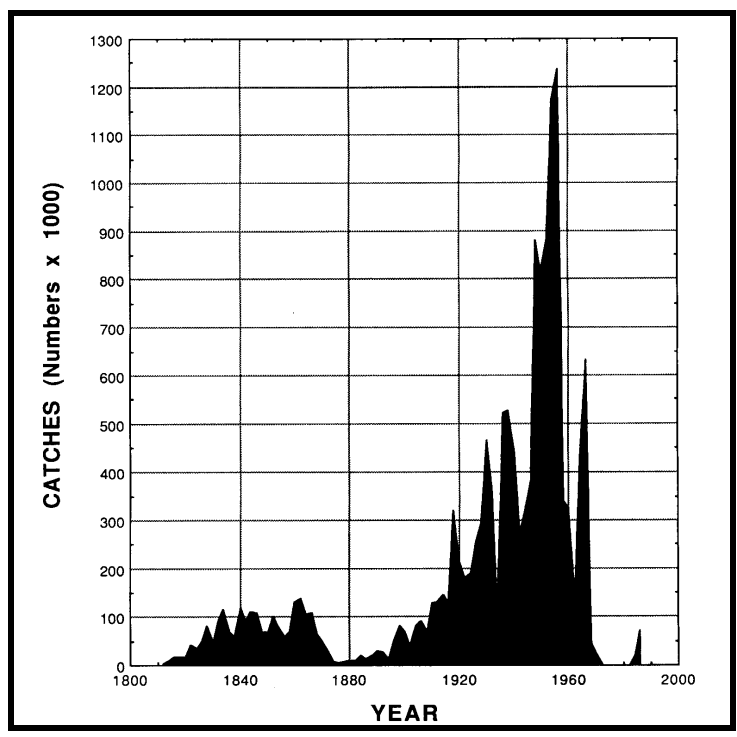

Fig. (13): The Solar Wolf-Gleissberg cycle evident in the catches of winter herring off western Norway with the superimposed spikes resembling individual sunspot cycles. Note the peak coincidence with the maximum of the Wolf-Gleissberg cycle (1957-59), with climate fluctuation happening soon after. The herring normally inhabit waters with temperatures between 3 and $13^{\circ} \mathrm{C}$, thus this fascinating diagram represents biological winter time series of the North sea temperature.

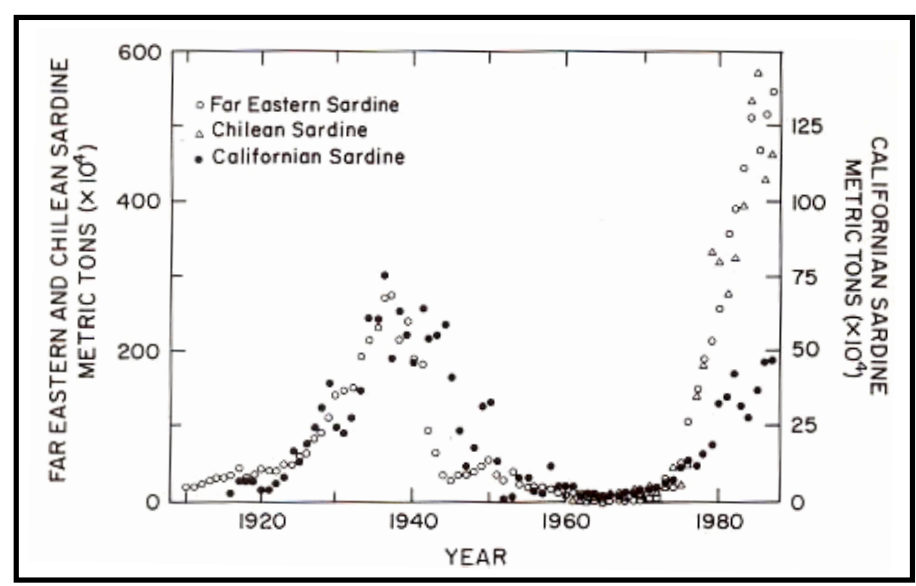

Fig. (14): Contemporary cyclic variation of sardine in the Pacific ocean attributed to solar induced climate change. The three populations started increasing in the 1920 s(1922 is the year of reversal of many sun-earth connections) with peaks in 1930 s, dropping to a very low level in 1960s. Another increase started in the $1970 \mathrm{~s}$ and peaked in the 1980s. 
Sardine has returned to the Egyptian shores and seen in the Markets of Portsaid, Damieta and Alexandria etc. The case of the rise and fall of the sardine is a global one and ought to be studied in the prospect of solar induced climate change.

The American lobster industry was subjected to a disaster in the 1920s ad 1930s (Acheson 1992). This can be explained in terms of solar forcing around 1922 with the termination of solar weak cycles and start of new Wolf-Gleissberg cycle affecting the solar radiation reaching the earth.

\section{B) Insect Population-A sensitive Climate Monitor}

Paleontologists have used fossil insects to show that rapid changes in climate can occur in only few years. Insects occupy one of the lower rungs of food chain., so fluctuations in their numbers may cause corresponding fluctuations in such predators as birds or spiders. Therefore correlating insect populations with solar activity is a worthwhile venture (Hoyt and Shatten, 1997).

\section{C) Temperature Effects on Plants}

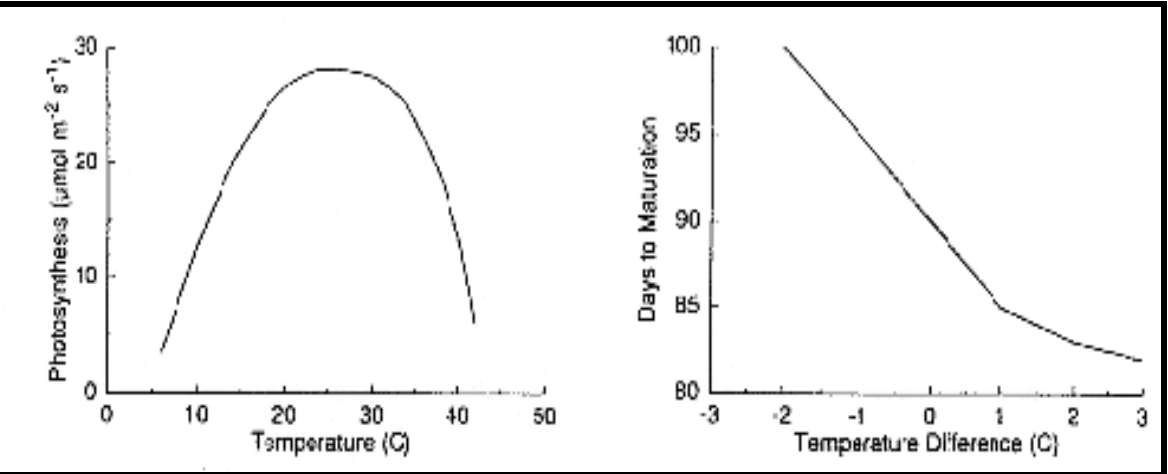

Fig. (15): Temperature effects on net photosynthesis, and effects of temperature from normal temperature on developmental rate (expressed as days to maturation). For reference, 10,25 , and $40{ }^{\circ} \mathrm{C}$ are equivalent to 50,77 , and $104{ }^{\circ} \mathrm{F}$. At $1{ }^{\circ} \mathrm{C}$ temperature difference is equivalent to a $1.8^{\circ} \mathrm{F}$ difference. 
Most plant processes related to growth and yield are highly temperature dependent. We can identify an optimum temperature range for maximum yield for any one crop. Crop species are often classified as warm- or cool-season types. The optimum growth temperature frequently corresponds to the optimum temperature for photosynthesis, the process by which plants absorb $\mathrm{CO}_{2}$ from the atmosphere and convert it to sugars used for energy and growth. Temperature also affects the rate of plant development. Higher temperatures speed annual crops through their developmental phases. This shortens the life cycle of determinate species like grain crops, which only set seed once and then stop producing and vise versa. Cooling would increase the life cycle of the plant. Our final fig, (Fig. 1 from Wolfe) illustrates the temperature effects on photosynthesis and crop growth duration. It shows that for a variety currently being grown in a climate near its optimum, a temperature increase(decrease) of several degrees could reduce (increase) photosynthesis and shorten (lengthen) the growing period. The particular crop varieties currently being grown in major production areas are usually those best-adapted to the current climate. A significant decrease in growing season temperatures will require shifts to new varieties that are more cool tolerant, do mature quickly, and have a lower temperature optimum for photosynthesis. Developing such varieties should be possible for many crop species, but there are limits to what can be accomplished. In many cases traditional crops will have to be abandoned for new crops better suited to the new environment. Some plant species require a cold period before they will produce flowers and a harvestable product. The process, called vernalization, tends to have very narrow temperature and duration boundaries. Vernalization of winter wheat, for example, requires temperature to be between 0 and $11^{\circ} \mathrm{C}$, with an optimum near $3^{\circ} \mathrm{C}$ for a period of 6 to 8 weeks. Production of the seed of many biennial vegetable crops has similar requirements. Even a minor climate shift of $1-2^{\circ} \mathrm{C}$ could have a substantial impact on the geographic range of these crops (Wolfe). 
The Irish potato crisis in 1878 occurred due to the sudden cooling at that time and lead to intensive immigrations to USA. In Egypt, the potatoes crop was very much affected by cooling few years ago, hence it is advisable to make intensive study on the effect of cooling on potatoes and if the result is very negative then it is advisable either to substitute the previously cultivated areas by a more tolerant crop to cooling.

Approximately $50 \%$ of the world's arable cropland is used for cereal production. The decline in grain (cereal) prices since 1950 has resulted from strong productivity growth in cereals in man regions in the world (Naylor, 2000). This yield increase was contemporary with the global temperature rise seen in fig 6 . The unusually sharp rise in rice, wheat and maize prices in 1973-1974 was caused by severe drought in Asia and the escalation of fossil fuel prices that disrupt the fertilizer market (Naylor, 2000).

\section{D) Temperature Effects on Livestock}

Climate change will affect livestock production indirectly by its impact on the availability and price of animal food. Farm animals are also directly affected by temperature. Animal species differ in their temperature optimum range. Young animals have a very narrow and specific temperature optimum. It is now well known that during some years, mammals such as rabbits and their predators are abundant, but are scarce in other years and seem to follow solar activity cycles (Hoyt and Shatten, 1997).

I have also noticed that certain epidemics spread with the decline of the Wolf-Gleissberg cycles around 1800, 1900 and 2000.

\section{Conclusions}

It has been shown that climatic parameters are very much dependant on Solar forcing as the pattern of those parameters closely resemble the 80 years Solar Wolf-Gleissberg cycles. 
Climate change do occur at the turning points of Solar WolfGleissberg cycles. Air and Sea surface temperature drops occur with the start of solar weak 12 years cycles i.e. with the drop of solar activity levels at the minimum of Solar Wolf-Gleissberg cycles. Such drops were noticed around 1800 and 1900 and should be coming soon as the present solar cycle number 23 is a weak cycle.

Such Global cooling would have far reaching biological effects affecting plants, animals, insects, fish and marine life. The cooling implications of such drop must be studied in details and forecasting models should be applied and used in future strategies on food production.

The rise and fall of the population of the Egyptian sardine can be attributed to solar induced climate changes and in coherence with the Pacific sardine cycles.

A comprehensive Egyptian agricultural strategy for the 1990s was published by the world bank(1993). An updated agricultural strategy for the first ten year of $21^{\text {st }}$ century should be put forward taking into account the expected cooling effect in Egypt and world wide. Agro-industries and fish tins could also be affected.

\section{Acknowledgements}

My sincere thanks are due to My mother Mrs. Ikram El Attar, to Dr. Hussein El Nouby and to Dr. Said Gaber.

\section{References}

- Abu El Ezz, M. S. 1980: World Climatic Fluctuations. Kuwait. In Arabic

- Acheson, J.M.1992:Maine Lobster Industry. In Climate Variability, Climate Change, and Fisheries. Edited by Michael Glantz. Cambridge University Press. pp 147-165. 
- Aesawy, A.M.and Hasanean, H.M. 1998: annual and seasonal Climatic Analysis of Surface Air Temperature Variation at Six Southern Mediterranean Stations. Theor. Appl. Climatol. 61, 55-68.

- Allen, C.W. 1973: Astrophysical Quantities, third edition, University of London. The Athions press.

- Donaire, Jaun José Sanz 2000: New definition of climate and climate change. Bulletin of the Egyptian Geographical Society, 73, 127-144.

- Gleissberg, W. 1971: Solar physics, 21, 240.

- Howard, R.1977: Solar Cycle, Solar Rotation and Large Scale Circulation. Illustrated

- Hoyt, D.V. and Schatten, K. 1997: The Role of The Sun In Climate Change. Oxford University Press.

- Krovnin A.S. and Rodionov, S.N.1992: Atlanto-Scandian herring: a case study. In Climate Variability, Climate Change, and Fisheries. Edited by Michael Glantz. Cambridge University Press, pp. 230-260.

- Kawasaki, T. 1992: Climate-dependant fluctuations in the Far Eastern sardine population and their impact on fisheries and society. In Climate Variability, Climate Change, and Fisheries. Edited by Michael Glantz. Cambridge University Press, pp. 325-354.

- Lamb H.H. 1966: Climate of the 1960s, Changes In World Wind Circulation Reflected In Prevailing Temperatures, Rainfall Patterns And The Level Of African Lakes. The geographical journal ,132, 183-212.

- Lamb H.H.1982: Climate History and The Modern World. Methuen London and New York.

- Lean J. 1997: The Sun's Variable Radiation And Its Relevance For Earth. Annual. Rev. Astron. Astrophys. 35: 33-67.

- Lean J. 2000: Short term, Direct Indices Of Solar Variability. Space Science Reviews 94, 39-51.

- Naylor, R.L. 000: Agriculture and Global change. Earth systems, processes and issues, pp. 462-475. Edited Y.W.G. Ernest. Cambridge University press.

- $\quad$ Nesme-Ribes E., Sokoloff D., Ribes, J.C. and Kremliovsky M. 1994: The Maunder minimum and the solar dynamo. NATO ASI series 25. The solar engine and its influence on tereestrial atmosphere and climate, Edited by Nesme-Ribes, 527. 
- Reid, G.R.1995: The sun-climate question: Is there a real connection? U.S. National Report to IUGG, 1991-1994 Rev. Geophys. Vol. 33 Suppl., (C) 1995 American Geophysical Union.

- Reid, G.C. 2000: Solar variability and the earth's climate: Introduction and review. Solar Variability and Climate; Edited by Friis-Christensen, E., Fröhlich, C., Haigh, J.D., Schüssler M. and Von Steiger R. Space Sci. Rev 94, No. 1-2

- Roberts, W. O. 1976: Since Technology and the modern Navy. The Thirtieth anniversary 1946-1976. Department of Navy, office of Naval research, Arlington, Virginia,371-368.

- Roederer, J.R. 1995: Solar variability effects on climate. In Solar output and climate during the Holocene, edited by Burkard Frenzel. Special issue, ESF project. European Paloeoclimate and man II. European Science Foundation. Strasbourg.

- Rosenzweig C. and Liverman D. 1992: Predicted Effects of Climate Change on Agriculture: A Comparison of Temperate and Tropical Regions. http://www.ciesin.org/docs/004-145/004145.html

- Schatten, K.H. and Orosz J.A. 1990: Geophysical Research Letters, 15, 179.

- Pap J. and White O.R. 1994: NATO ASI series 25. The solar engine and its influence on terrestrial atmosphere and climate, Edited by Nesme- Ribes, 235.

- Ueber, W. and MacCall,A. 1992: The rise and fall of the California sardine empire. In Climate Variability, Climate Change, and Fisheries. Edited by Michael Glantz. Cambridge University Press. pp 31- 48.

- Yousef, Shahinaz Moustafa 1995: The Downturn of Solar Activity During The Forthcoming Three Cycles. Bull: Fac.Sc. Cairo Univ., 63, pp 185-192.

- Yousef, Shahinaz Mustafa, and El Raey M. 1995: Major Solar Episodes Reconstructed Using Records of The River Nile, TreeRing Indices and Sunspots. Bulletin De L'Institut D'Egypte. Tomes LXXIV, p 76. 
- Wolfe David W.: Potential Impact of Climate Change on Agriculture and Food Supply Sustainable Development and Global Climate Change Conference http://www.gcrio.org/ USGCRP/sustain/wolfe.html

- World bank Country Study 1993: Arab republic of Egypt, An agricultural strategy for the 1990s.

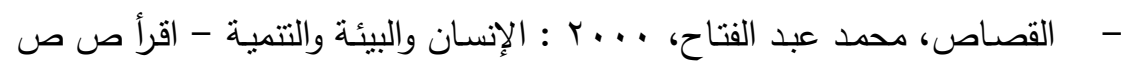

L T07، IV7 - دار المعارف، مصر.

$* \quad * \quad *$

$-80-$ 
وعليه بمكن القول أن التغيرات الدورية فى وفرة الأسماك مرنبطة بعضها بالبعض فى

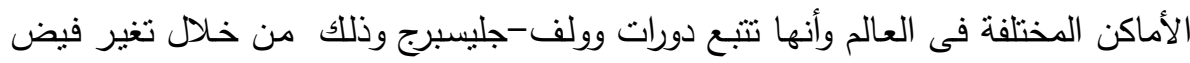
الإثعاعات الثمسية والتى تمتص على أعماق مختلفة فى المياه مما يؤدى إلى تغيرات فى دي

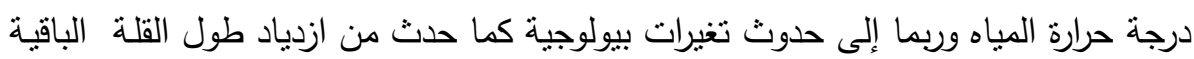
من أسماك السردين عند ندرته.

إن تأثثر البرودة على الزراعة فى غاية الأهمية حيث قدرت دراسات سابقة أن انخفاض

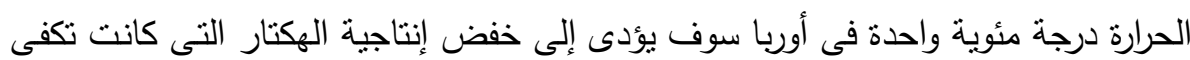
ثلاثة أثخاص إلى ما يكفى شخصين فقط مع تعرض خمس سكان العالم إلى مجاعة. وإنني أدعو الباحثين دعوة عاجلة إلى تطبيق برامج الكومبيوتز لحساب تأثير انخفاض أنسا.

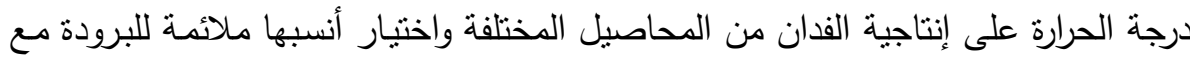
إمكانية زراعة نفس المحصول فى عروض أكثر انخفاضا.

كما إننى أدعو الحكومة المصرية إلى وضع استراتيجية زراعية معدلة مراعية فيها

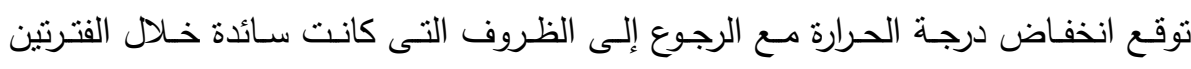

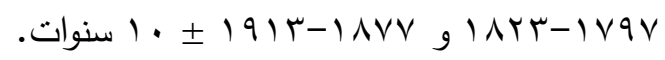




\section{توقع برودة الأرض وتأثيرها على الأمن الغذائى}

\section{د. شاهناز مصطقى على يوسف}

إن التغيرات المناخية الناجمة عن تغيرات فى الثمس تؤئز تأثثرا حرجا على الحياة

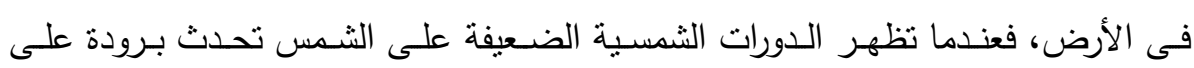

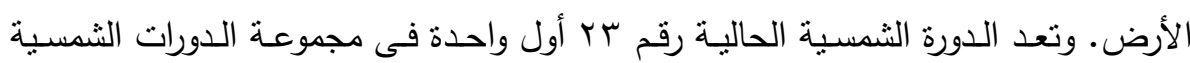

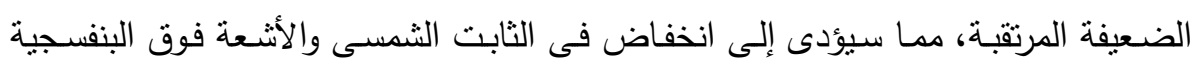

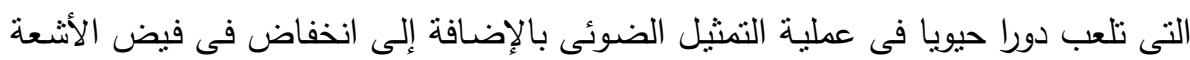

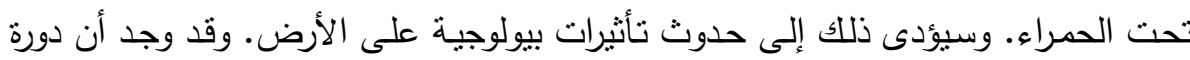

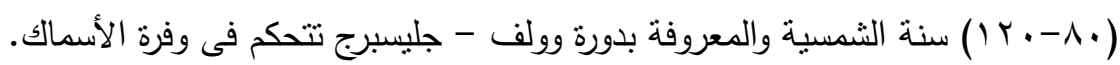

إن اختفاء سمك السردين تقريبا من شرق البحر المتوسط فى عام ع 97 الم يكن

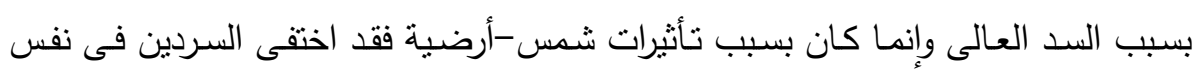

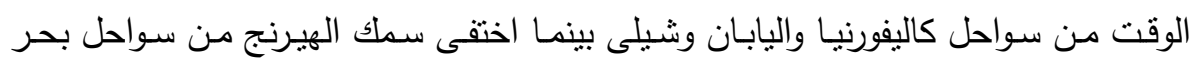

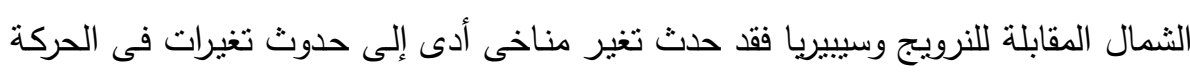
العامة للرياح. ويمكن أعزاء التغير المناخى فى أوائل الستينات إلى انخفاض مستوى النشاط الثمسى

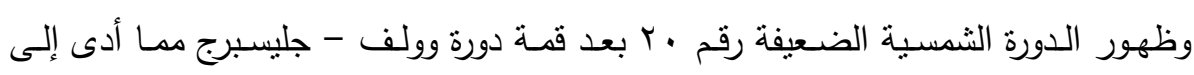
الإسراع فى دوران الثمس حول محورها. *- فسم الفلك والأرصاد الجوية، كلية العلوم - جامعة القاهرة. 